\title{
Properties of poly(vinyl alcohol) films as determined by thermal curing and addition of polyfunctional organic acids
}

\author{
Massimo Bellellia, Fabio Licciardello ${ }^{\mathrm{a}, \mathrm{b}}$, , Andrea Pulvirenti ${ }^{\mathrm{a}, \mathrm{b}}$, Patrizia Fava ${ }^{\mathrm{a}, \mathrm{b}}$ \\ ${ }^{a}$ Department of Life Sciences, University of Modena and Reggio Emilia, Via Amendola 2, 42122, Reggio Emilia, Italy \\ ${ }^{\mathrm{b}}$ Centro di Ricerca Interdipartimentale per il Miglioramento e la Valorizzazione delle Risorse Biologiche Agro-Alimentari BIOGEST-SITEIA, University of Modena and Reggio Emilia, Tecnopolo di \\ Reggio Emilia, Piazzale Europa 1, 42124, Reggio Emilia, Italy
}

\section{ART ICLE INFO}

Keywords:

Citric acid

Crosslinking

Malic acid

Plasticizer

$\mathrm{PVOH}$

\begin{abstract}
A B S T R A C T
The aim of the study was to assess the effect of the addition of citric and malic acid and heat curing on the mechanical, physical and optical properties of poly(vinyl alcohol) ( $\mathrm{PVOH})$ films. The addition of the organic acids without successive thermal treatments has a mere plasticising effect, while their application with heat curing has a combined crosslinking and plasticising effect. While conventional plasticizers and crosslinkers improve either extensibility or tensile strength of films, respectively, the addition of citric and malic acid coupled with heat curing determined good tensile strength and extensibility. Hydrophilicity was significantly reduced by thermal curing and even further reduced with the organic acids addition. The high transparency of the PVOH films was not affected either by heat-curing, acid addition and their combination, while the use of high curing temperature coupled with acid addition caused a slight yellowing of the films. The use of citric and malic acid in combination with thermal curing is a viable strategy for tailoring the performances of PVOH films thus broadening their spectrum of application.
\end{abstract}

\section{Introduction}

Poly(vinyl alcohol) (PVOH) is a non-toxic, odourless and tasteless polymer with several applications, such as food packaging material (as film, layer in composite films, coating for films of different nature), as a coating agent for food supplements, in the pharmaceutical and cosmetics industries and several medical applications, as well as in the paper and textile industries (Demerlis \& Schoneker, 2003; Vieira, Altenhofen da Silva, Oliveira dos Santos, \& Beppu, 2011). PVOH has been previously evaluated for safety by the Joint FAO/WHO Expert Committee on Food Additives (JECFA) in 2003 at the 61st meeting, and an ADI of $50 \mathrm{mg} / \mathrm{kg}$ bw was established.

Among its main features, biodegradability has raised interest for this material (Chiellini, Corti, d'Antone, \& Solaro, 2003); indeed, even boosted by the recent planetary alert on microplastic pollution, research is seeking for biodegradable packaging solutions which could substitute conventional plastics for food application, considering that recycling is often not feasible for food packaging plastics (Gan \& Chow, 2018; Ingrao, Gigli, \& Siracusa, 2017).
As a material for food packaging, either as stand-alone material or in the formulation of composite films (Muppala, Kannat, Chawla, \& Sharma, 2014), PVOH generally stands out for its excellent film-forming capacity, barrier to gases, optical properties, high tensile strength and flexibility (Park, Park, \& Ruckenstein, 2001; Park, Jun, \& Marsh, 2001); however, the physical properties of $\mathrm{PVOH}$ largely depend on the method of preparation. On the other hand, $\mathrm{PVOH}$ is highly hydrophilic and its properties are affected by water acting as plasticizer (Musetti et al., 2014). Hence, research aimed at the improvement of PVOH properties is of paramount importance in order to broaden its range of application. Previous works have studied the physical and mechanical response of PVOH films to curing: this can be performed by heat treatment, addition of cross-linking agents or both. Chemical cross-linking agents which have been studied for $\mathrm{PVOH}$ are glutaraldehyde, hexamethylene diisocyanate, glyoxal and boric acid (Lim et al., 2015). Multifunctional compounds able to react with the hydroxyl groups present in each repeating unit of $\mathrm{PVOH}$ may be used as crosslinkers and yield three-dimensional networks, thus enhancing resistance to dissolution in water, improving mechanical and thermal properties (Lim et al., 2015):

\footnotetext{
* Corresponding author at: Department of Life Sciences, University of Modena and Reggio Emilia, Via Amendola 2, 42122, Reggio Emilia, Italy.

Email address: fabio.licciardello@unimore.it (F. Licciardello)
} 
it is the case of dialdehydes, dicarboxylic acids and dianhydrides (Gohil, Bhattacharya, \& Ray, 2006).

A cross-linking agent generally reduces hydrophilicity and improves tensile strength at the expense of the extensibility (thus, brittleness increases) of the film, and this effect has been proven on PVOH (Lim et al., 2015). However, the use of alternative curing agents has not received sufficient attention. Since PVOH is a biodegradable material, natural-based, "green" curing agents should be preferred to conventional cross-linkers (such as glutaraldehyde) used in the formulation of conventional, non-biodegradable plastics.

In the perspective of tailoring $\mathrm{PVOH}$ performances thus widening its spectrum of application, the present study aimed at developing $\mathrm{PVOH}$ films by formulation with two organic acids used as food ingredients, namely citric acid (E330) and malic acid (E296) and thermal curing, assessing the effect of treatments on the mechanical properties, water absorption and water solubility and optical properties.

\section{Materials and methods}

\subsection{Materials}

Commercial PVOH powder (Mowiol ${ }^{\circledR}$ 10-99, $\mathrm{M}_{\mathrm{w}}=145,000 \mathrm{~g} \cdot \mathrm{mol}^{-1},>99 \%$ hydrolysis), analytical grade DL-malic acid and citric acid (assay 98\%) were purchased from Sigma Aldrich (Milan, Italy).

\section{2. $\mathrm{PVOH}$ films preparation}

PVOH solutions in distilled water were obtained by heating in a water bath at $90^{\circ} \mathrm{C}$ under constant stirring for $5 \mathrm{~h}$. PVOH/plasticizer solutions (total solids $5 \% \mathrm{w} / \mathrm{w}$ ) were prepared mixing previously prepared $\mathrm{PVOH}$ solution with suitable volumes of citric or malic acid solution, in order to obtain film-forming solutions containing 10, 20, 30 and $40 \%$ plasticizer on the total solid basis.

Ten grams of each film-forming solution were casted onto Petri dishes and air-dried for $24 \mathrm{~h}$ at $35^{\circ} \mathrm{C}$. Curing was performed heating the experimental PVOH films at different temperatures $\left(75,100\right.$ and $\left.125^{\circ} \mathrm{C}\right)$ in a ventilated oven for $20 \mathrm{~min}$.

\subsection{Characterization of $\mathrm{PVOH}$ films properties}

\subsubsection{Film thickness measurement}

The thickness of film was measured by a micrometer (Mitutoyo Absolute, Japan). The mean thickness was calculated from figures obtained on 5 random locations along the surface of each of the 3 plastic material strips cut from 3 replicates of the film.

\subsubsection{Water absorption}

To estimate the degree of water absorption, 3 specimens $(2.0 \times 2.0 \mathrm{~cm})$ of known weight $\left(\mathrm{W}_{0}\right)$ cut from 3 replicates of the film, were soaked separately in $80 \mathrm{~cm}^{3}$ of Millipore water for $24 \mathrm{~h}$ (to reach equilibrium) at $30^{\circ} \mathrm{C}$. The sample films were then removed from the solution and placed onto a filter paper to drain the excess of water and weighed $\left(\mathrm{W}_{\mathrm{e}}\right)$. The degree of water absorption (WA) was calculated as grams of water per grams of sample by the following Eq. (1):

$\mathrm{WA}=\left(\mathrm{W}_{\mathrm{e}}-\mathrm{W}_{0}\right) / \mathrm{W}_{0} \times 100$

\subsubsection{Degree of solubility}

To determine the potential release of material from the plastic matrix, caused by moisture absorption, 3 samples $(2.0 \times 2.0 \mathrm{~cm})$ cut from 3 replicate film were used. After drying to constant weight in a desiccator, each sample was weighed $\left(W_{0}\right)$ and then soaked into $40 \mathrm{~cm}^{3}$ deionized water, inside a stoppered glass flask. After $72 \mathrm{~h}$, samples were removed, and the excess surface water was drained. Each sample was dried for $24 \mathrm{~h}$ at $60^{\circ} \mathrm{C}$ and then placed under vacuum until a constant weight $\left(\mathrm{W}_{\mathrm{d}}\right)$

The solubility (S) was calculated by the following Eq. (2):

$\mathrm{S}=\left(\mathrm{W}_{0}-\mathrm{W}_{\mathrm{d}}\right) / \mathrm{W}_{0} \times 100$

\subsubsection{Mechanical properties of films}

Tensile strength (TS, MPa) and elongation at break (E, \%) were measured for each film by a dynamometer testing machine (Zwick/ Roell Model BT1-FR1.0TH.140) according to ASTM D882-12, using the following conditions: grip distance $50.0 \mathrm{~mm}$; crosshead speed $20 \mathrm{~mm}$ / min, load cell of $1 \mathrm{kN}$. Three rectangular samples sized $70 \mathrm{~mm}$ x $10 \mathrm{~mm}$ (length $\times$ width) were cut from each film and each specimen had an average thickness of $0.06 \mathrm{~mm}$. Before testing, all samples were conditioned for not less than $40 \mathrm{~h}$ at $23 \pm 2{ }^{\circ} \mathrm{C}$ and $50 \pm 10 \%$ relative humidity.

\subsubsection{Determination of film color and transparency}

The color of PVOH films was determined by the CIE L*a*b* system using a portable colorimeter (Hunter Associates Laboratory, Inc., Reston, Virginia, USA). The overall color change in comparison with virgin (i.e. non-cured and not added with organic acids) PVOH samples was calculated as follows:

$\Delta \mathrm{E}^{*}=\left(\Delta \mathrm{L}^{* 2}+\Delta \mathrm{a}^{* 2}+\Delta \mathrm{b}^{* 2}\right)^{1 / 2}$

Where $\Delta \mathrm{L}^{*}, \Delta \mathrm{a}^{*}$ and $\Delta \mathrm{b}^{*}$ are the differences between the $\mathrm{L}^{*}, \mathrm{a}^{*}, \mathrm{~b}^{*}$ value of the treated sample (with various combinations of acid/curing temperature), and the $L^{*}, a^{*}$ and $b^{*}$ color coordinates of virgin films.

Transmittance at $600 \mathrm{~nm}$ was measured by UV--vis spectrophotometer (Jasco V530, Tokyo, Japan) as described by Shiku et al.(2004) and the transparency values were calculated by Eq. (4) (Han \& Floros, 1997).

Transparency value $=-\left(\log \mathrm{T}_{600}\right) / \mathrm{x}$

where $\mathrm{T}_{600}$ is the fractional transmittance at $600 \mathrm{~nm}$ and $\mathrm{x}$ is the film thickness (mm). The greater value represents the lower transparency of the film.

\subsection{Statistical analysis}

Mechanical, physical and optical data were subjected to a two-way analysis of variance (ANOVA) as a factorial combination of curing temperature (4) $\times$ citric or malic acid concentration (5). Means were separated by the Tukey test and by the Least Significant Difference (LSD) test. Data statistical analysis was performed using IBM SPSS ${ }^{\circledR}$ for Windows version 13.0.1 (Armonk, NY, USA).

\section{Results and discussion}

\subsection{Effect of organic acids and thermal curing on the mechanical properties of $\mathrm{PVOH}$ films}

The study aimed at assessing the effect of organic acids level and curing temperature on the mechanical properties of $\mathrm{PVOH}$ films, with special focus on tensile strength (MPa) and elongation at break (\%). Mechanical data submitted to factorial ANOVA (Table 1) proved a significant effect $(\mathrm{p}<0.05)$ of the single factors (organic acid and curing temperature) and of their interaction in the observed variance. As it can be inferred from Fig. 1, the increase in the citric and malic acid level (from 0 to $40 \%$ ) determined a progressive reduction of the tensile strength by up to 63 and $56 \%$ in non-cured PVOH films added with $40 \%$ citric and malic acid, respectively. Conversely, a progressive increase in the elongation at break was observed with increasing citric and malic acid levels: in particular, extensibility of the control film was 
Table 1

Results (F-values) from two-way ANOVA of mechanical, physical and optical data, showing the effect of main factors and their interaction.

\begin{tabular}{|c|c|c|c|c|c|}
\hline Source of variation & Df & Tensile strength & Elongation at break & Water absorption & Transparency \\
\hline Curing temperature $(\mathrm{T})$ & 3 & $5.02^{* *}$ & $15.58 * * *$ & $159.79 * * *$ & $5.21^{* *}$ \\
\hline Citric acid (C) & 4 & $4847.56^{* * *}$ & $43.42^{* * *}$ & $22.58^{* * *}$ & $20.49 * * *$ \\
\hline $\mathrm{T} \times \mathrm{C}$ & 12 & $154.62^{* * *}$ & $9.10^{* * *}$ & $4.47^{* * *}$ & $5.39 * * *$ \\
\hline Total meansquare & & 5114.4 & $49,787.5$ & $1,533,616.4$ & 0.231 \\
\hline Curing temperature $(\mathrm{T})$ & 3 & $0.81^{\mathrm{ns}}$ & $6.31^{* * *}$ & $138.34^{* * *}$ & $17.36^{* * *}$ \\
\hline Malic acid (M) & 4 & $181.41^{* * *}$ & $41.09 * * *$ & $45.63^{* * *}$ & $2.74^{*}$ \\
\hline $\mathrm{T} \times \mathrm{M}$ & 12 & $3.99^{* * *}$ & $8.02^{* * *}$ & $5.93^{* * *}$ & $3.87^{* * *}$ \\
\hline Total mean square & & 4376.3 & $28,488.1$ & $1,301,929.6$ & 0.149 \\
\hline
\end{tabular}

Df: degree of freedom. ${ }^{* * *} \mathrm{p}<0.001 ;{ }^{* *} \mathrm{p}<0.01 ;{ }^{*} \mathrm{p}<0.05$; ns: not significant.

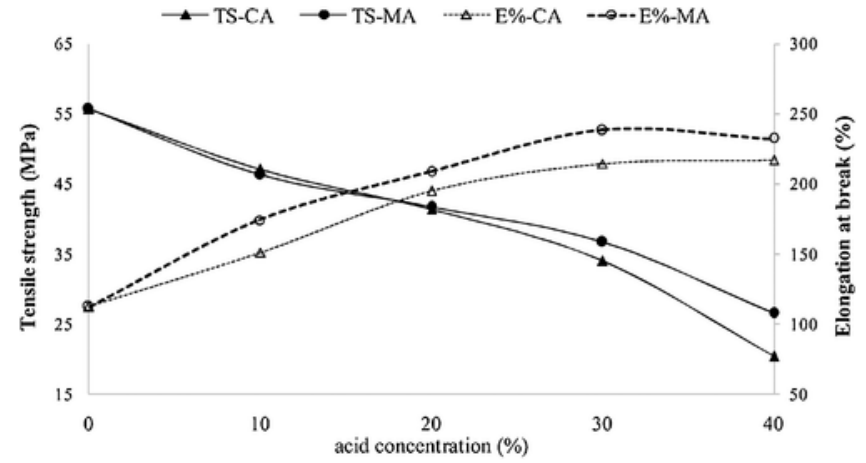

Fig. 1. Tensile strength (TS) and elongation at break (E\%) of non-cured PVOH films added with variable levels of citric (CA) and malic acid (MA).

$112 \%$, raising up to 217 and $238 \%$ in the films added with $40 \%$ citric and $30 \%$ malic acid, respectively. As it can be inferred from Fig. 1, citric and malic acid provided comparable mechanical patterns in non-cured films.

The net effect of curing temperature on the mechanical properties of pure PVOH films can also be inferred from data in Figs. 1 and 2. Tensile strength did not change significantly between $35^{\circ} \mathrm{C}(55.66 \mathrm{MPa})$ and $75^{\circ} \mathrm{C}(54.95 \mathrm{MPa})$, while it showed a significant increase at $100{ }^{\circ} \mathrm{C}$, decreasing again, though not significantly, after treatment at $125^{\circ} \mathrm{C}$; elongation at break increased significantly with temperature, and the effect was more marked between $35^{\circ} \mathrm{C}(112 \%)$ and $75^{\circ} \mathrm{C}(175.5 \%)$ (about 1.6 elongation percentage points per ${ }^{\circ} \mathrm{C}$ ) compared to the step $75-100{ }^{\circ} \mathrm{C}$ (about 1 percentage point per ${ }^{\circ} \mathrm{C}$ ). Thermal treatment without plasticizer determined an overall improvement of mechanical properties, in agreement with previous findings: in particular, Yoon (2014) proved that tensile strength, elongation at break, thermal properties and water resistance of $\mathrm{PVOH}$-starch films improved by $65-295 \%$ through heat curing.

From a comparison of mechanical data of $\mathrm{PVOH}$ films including the two organic acids, it appears that malic acid exerted the maximum plasticizing effect at lower concentrations, while citric acid showed plasticizing capacity, increasing elongation, until $40 \%$. Indeed, films including citric acid showed the maximum values for elongation at break at $40 \%$ and curing at 75 and $100{ }^{\circ} \mathrm{C}$, while malic acid yielded the highest results at $30 \%$ coupled with curing at 75 and $100{ }^{\circ} \mathrm{C}$. The same plasticizing effect was confirmed also in non-cured films, where, for a given concentration, malic acid determined higher $\%$ elongation compared with citric acid.

The analysis of mechanical properties data after different heat curing treatments reveals a duplex role played by the organic acids in the polymeric matrix, as a function of temperature and concentration. Indeed, the plot for the non-cured films (Fig. 1) showed a typical plasticizer behaviour, producing a decrease of tensile strength and an increase in the elongation at break at increasing citric and malic acid concentrations, according to other experimental evidences (Mohsin,
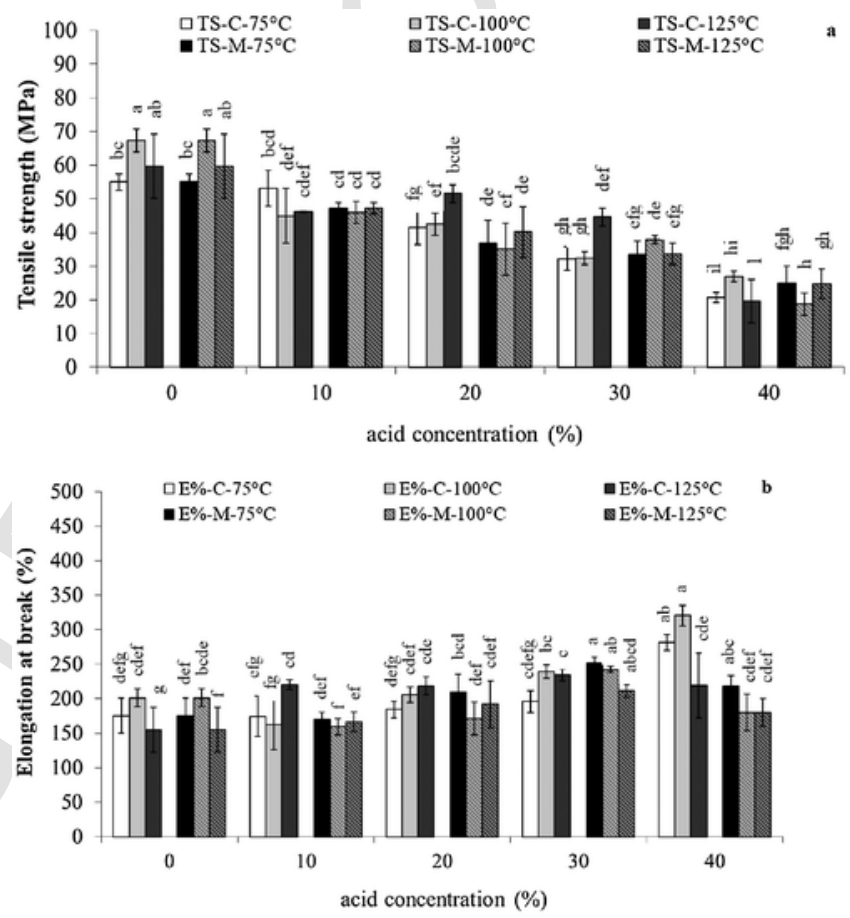

Fig. 2. Tensile strength (a) (TS) and Elongation at break (b) (E\%) of $\mathrm{PVOH}$ films added with variable levels of citric (C) and malic acid (M) and cured at $75^{\circ}, 100^{\circ} \mathrm{C}$ and $125^{\circ} \mathrm{C}$.For each group of samples, i.e. samples added with citric acid (C) and samples added with malic acid (M), different letters highlight statistically significant differences ( $p>0.05$ ), according to the Tukey test.

Hossin, \& Haik, 2011; Park, Park et al., 2001; Park, Jun et al., 2001; Yoon, Chough, \& Park, 2007; Yoon, 2014). Non-cured films showed a clear inverse correlation $(\mathrm{r}=-0.899, \mathrm{p}>0.05$ for citric acid; $\mathrm{r}=-0.906, \mathrm{p}>0.05$ for malic acid) between tensile strength and \% elongation, while the correlation values decreased with treatment temperature, being not significant for samples treated at 100 and $125^{\circ} \mathrm{C}$. This result suggested that a change in the molecular organization of the PVOH matrix had occurred.

The mechanical behaviour observed after curing is clearly different from that observed for non-cured films, highlighting a combined plasticizing and crosslinking function of the organic acids, the latter activated by temperature. Indeed, at these conditions, part of the carbonyl groups of citric and malic acid are involved in esterification reactions with hydroxyl moieties of $\mathrm{PVOH}$, which increase the molecular interactions, resulting in higher mechanical properties. At intermediate temperatures, the lower crosslinking effect is counterbalanced by the plasticizing effect of the unreacted acid fraction. Mechanical tests showed that cured films maintained both good tensile strength and elongation at break values until $20 \%$ acid addition, while at the highest acid concentrations a significant decrease of tensile strength was observed, 
which suggests the effect of excess acid acting as plasticizer. However, it must be noted that even if tensile strength was lost at high acid concentrations, the elongation at break, which had been significantly improved with citric and malic acid addition remained high, as to testify the structural improvement achieved in the PVOH matrix with crosslinking.

Hence, the use of citric and malic acid in the range of $20-30 \%$ coupled with curing at $100-125^{\circ} \mathrm{C}$ represents a good strategy for improving flexibility and maintaining good strength of $\mathrm{PVOH}$ films. A crosslinking agent generally improves tensile strength at the expense of the extensibility of the film. Birck, Degoutin, Tabary, Miri, and Bacquet, (2014) assessed the effect of crosslinking at $130{ }^{\circ} \mathrm{C}$ for various durations of time, on the thermal and mechanical properties of PHOV-citric acid films, finding that $40 \%$ citric acid led to a high degree of crosslinking, which resulted in film brittleness. Hence, they focused on $10 \%$ citric acid, they studied the effect of crosslinking time on the mechanical properties and reported that the elongation at break decreased while the tensile strength increased with crosslinking time; the observed behaviour was due to the effects of crosslinking at the molecular level, which enhanced rigidity and reduced the extensibility of chains. Our study points out that the advantage of using a bifunctional (crosslinker and plasticizer) compound such as citric and malic acid consists in the possibility to obtain films with good tensile strength and improved extensibility. It is possible, however, that the use of even higher curing temperatures or longer curing times would boost the esterification reactions, thus reducing the unreacted part of organic acids and the plasticizing effect observed. Therefore, the control of curing temperature, duration and curing agent concentration are determinant for obtaining desired mechanical properties of PVOH films.

\subsection{Effect of organic acids and thermal curing on water absorption and solubility}

Water absorption (WA) is a measure of hydrophilicity and is highly influenced by the nature and structure of the polymer, crosslinking, characteristics of the liquid phase and temperature. For this reason, WA values of PVOH films vary widely among literature data. For instance, equilibrium WA values reported in previous studies vary from around $32 \%$ (Shi et al., 2008), to 120\% (Liu, Zheng, \& Tang, 2013), 250\% (Pawde \& Deshmukh, 2008), about 800\% (Quintero et al., 2010) and up to $1200-1800 \%$ in our previous work (Musetti et al., 2014). Quintero et al. (2010) demonstrated that the WA degree in PVOH-polyacrylic acid hydrogels decreases with increasing ionic strength, indeed they observed low WA values at higher saline concentrations and WA values around $800 \%$ for samples immersed in the solution with lower ionic strength: such value is comparable with our values obtained after contact of virgin $\mathrm{PVOH}$ with distilled water.

Heat curing without addition of organic acids in the film formulation led to a decrease of both WA (from $859 \%$ for not cured films to $218 \%$ after curing at $125{ }^{\circ} \mathrm{C}$ ) and solubility (from $40 \%$ for films cured at $35{ }^{\circ} \mathrm{C}$ to $9.7 \%$ after curing at $125^{\circ} \mathrm{C}$ ) (Fig. 3). Similarly, Yoon (2014) demonstrated that the WA degree of potato starch-PVOH films without plasticizer decreased with curing temperature and time. Moreover, Gohil et al. (2006) observed that heat treatment of PVOH determines a many-fold gain in resistance to WA compared to virgin $\mathrm{PVOH}$, and they attributed such improvement to the elimination of water and to the alignment of polymeric chains, with a consequent loss of polar nature. Indeed, it has been reported that the WA degree decreases as the esterification and crosslinking degree increase (Shi et al., 2008; Zou, Qu, \& Zou, 2007).

Our results suggest that the WA reduction in $\mathrm{PVOH}$ films was not only related with heat treatment or crosslinking which, indeed, seems to occur at $100^{\circ} \mathrm{C}$ or $125^{\circ} \mathrm{C}$ (see comments on mechanical properties), but it was also strongly dependant on the acids concentration. The ef-

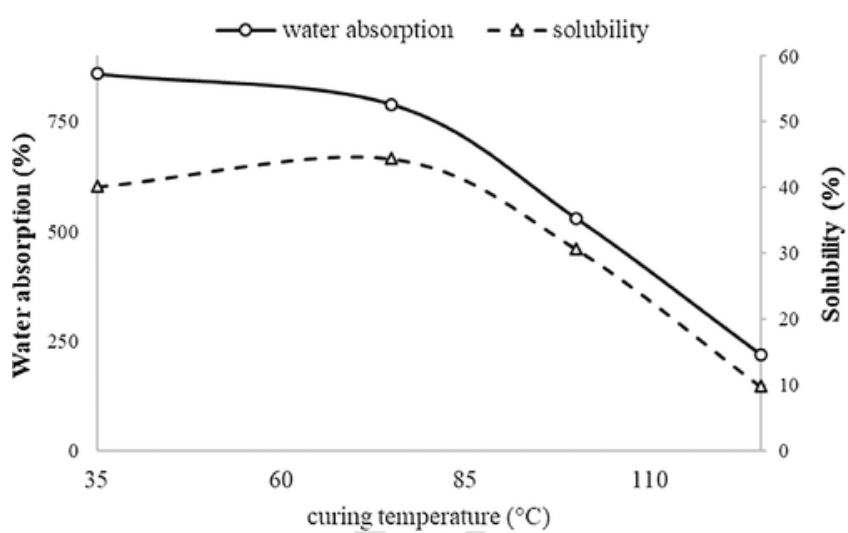

Fig. 3. Effect of curing temperature on water absorption and solubility of PVOH films not added with organic acids.

fect of acids addition on the decrease of WA was more evident in the films cured at lower temperatures. For the films cured at each of the tested temperatures, a significant WA reduction was observed with increasing citric and malic acid addition (Fig. 4). For non-cured films, a slight increase in WA was observed with $10 \%$ citric or malic acid addition, followed by significant decrease with further additions. With the only exception of PVOH film added with citric acid and not cured, all samples showed WA values which were much (from 2- to about 5-fold) lower than those of the virgin film. Interestingly, the WA levels in films added with $40 \%$ citric acid was similar for curing at 75,100 and $125^{\circ} \mathrm{C}$, while the difference increased at the lower acid concentrations. A similar effect of citric acid was observed by Zou et al. (2007) who re-
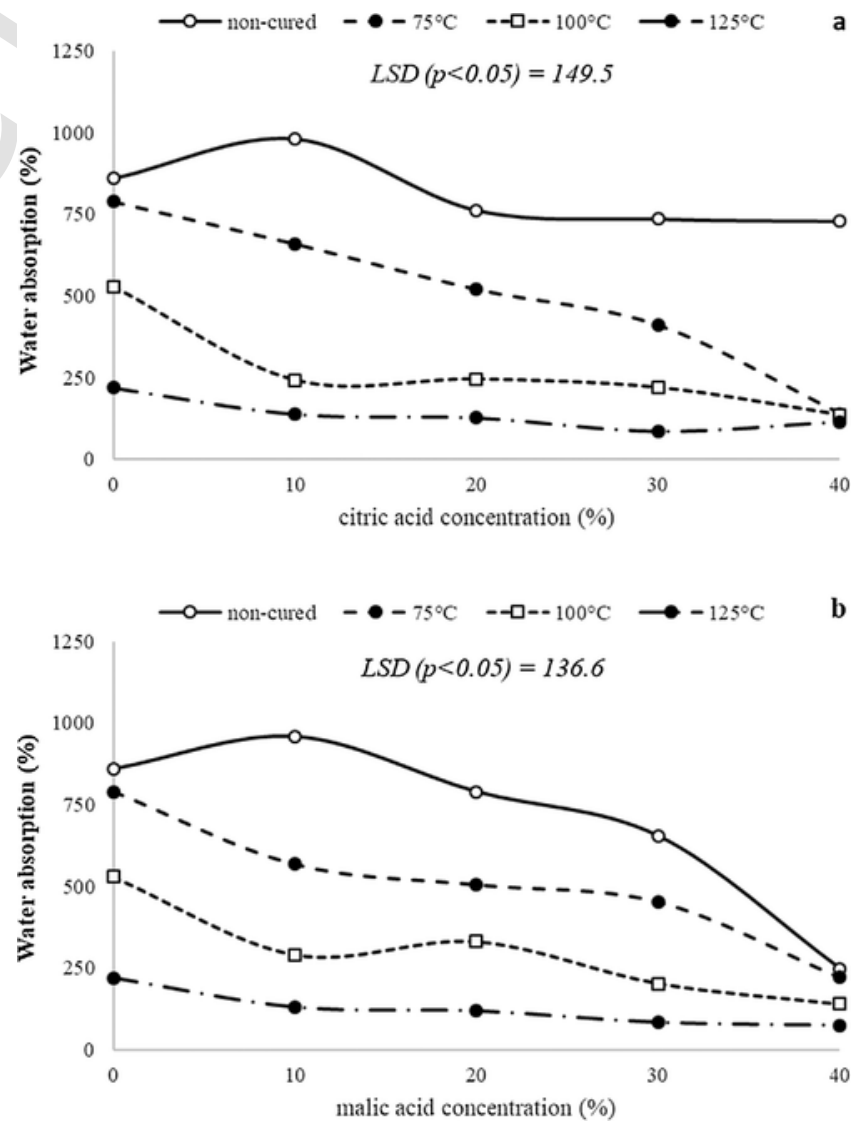

Fig. 4. Effect of citric (a) and malic (b) acid addition on water absorption of PVOH films cured at different temperatures. Significance of difference among means is based on the least significant difference (LSD) for $\mathrm{p}<0.05$. 
ported a significant reduction of WA of starch/PVOH composite films with the addition of citric acid and glycerol, thus proving the effect of the plasticizer at reducing the hydrophilicity of the films. Also, our results were consistent with previous findings by Yoon (2014), who observed a lower WA degree in films cured with ascorbic acid compared to the blank films, and Gohil et al. (2006), who found decreasing WA degree with increasing maleic acid doses at three curing temperatures.

This result can be explained under the following (one or both) hypotheses: $i$ ) esterification between carboxylic groups on organic acids and hydroxyl groups on $\mathrm{PVOH}$ occurs during mixing of the film-forming solutions (irrespective of the curing temperature); as it has been stated, the degree of esterification improves water resistance and this might explain the observed lower WA with increasing acids concentration; ii) interaction (hydrogen bonding) of the hydroxyl groups of the PVOH with those of citric and malic acid, both of which have one -OH moiety available for interaction: under this event, some of the $-\mathrm{OH}$ of the matrix are subtracted to interaction with water, thus reducing water affinity.

Conversely, we observed a slight increase in solubility with the organic acid addition to the film formulation; however, this result is to be considered only apparent and should be attributed to the release of the acid from the film rather than to the dissolution of the film itself. Indeed, the apparent solubility slightly increases with increasing acid concentration, that is to say, with increasing levels of unreacted (unbound) curing compound. This phenomenon is a desired event, representing the fundamental feature of an active packaging film meant to release an active compound in the packaged food.

\subsection{Effect of organic acids and thermal curing on $\mathrm{PVOH}$ films color and transparency}

$\Delta \mathrm{E}^{*}$ is the total color variation, given by the contribution of the single color coordinates $\mathrm{L}^{*} \mathrm{a}^{*} \mathrm{~b}^{*}$. In this study, we assessed the $\Delta \mathrm{E}^{*}$, which estimates the color changes with respect to the virgin $\mathrm{PVOH}$ films (i.e. not added with organic acids and not cured).

As shown in Fig. 5, thermal curing did not affect the color of pure $\mathrm{PVOH}$ film samples, as measured through the $\mathrm{L}^{*} \mathrm{a} \mathrm{b}^{\mathrm{b}}$ chromatic coordinates, indeed the overall color variation, expressed as $\Delta \mathrm{E}^{*}$, was practically unchanged for the different heat treatments as compared with the non-cured films. On the other hand, thermal curing of films incorporating organic acids at different levels did affect the color of the films. In particular, $\Delta \mathrm{E}^{*}$ was mostly determined by the increase in the $\mathrm{b}^{*}$ value, which corresponded to the slight browning occurring in the films cured at high temperature, probably due to a slight thermal degradation of the two organic acids.

The effect of temperature was synergistic with that of acid concentration. Indeed, color changes were hardly noticeable at $75{ }^{\circ} \mathrm{C}$, where a $\Delta \mathrm{E}^{*}$ of 0.09 and 0.06 was calculated for the highest malic and citric acid concentration, respectively, while a proportional and exponential effect of acid concentration was observed at $100^{\circ} \mathrm{C}$ and $125^{\circ} \mathrm{C}$. Overall color change was dependent on both the acid concentration and on thermal curing, while the type of organic acid did not play a noticeable role.

Interestingly, the films where an increase of $b^{*}$ had occurred, still maintained high transparency, which characterizes PVOH films. The yellowness of PVOH films should be considered as a side-effect of acid incorporation and heat curing, however, this is not necessarily a drawback and, in fact, the light-amber color developed could exert a protective role on sensitive food components against certain radiations.

$\mathrm{PVOH}$ films commonly stand out for their transparency: our results demonstrated that transparency was maintained also after curing, even when the curing conditions determined significant color changes (yellowing). Transparency values (data not shown) ranged between 0.51 and 0.69 for films added with malic acid, and between 0.63 and 0.81
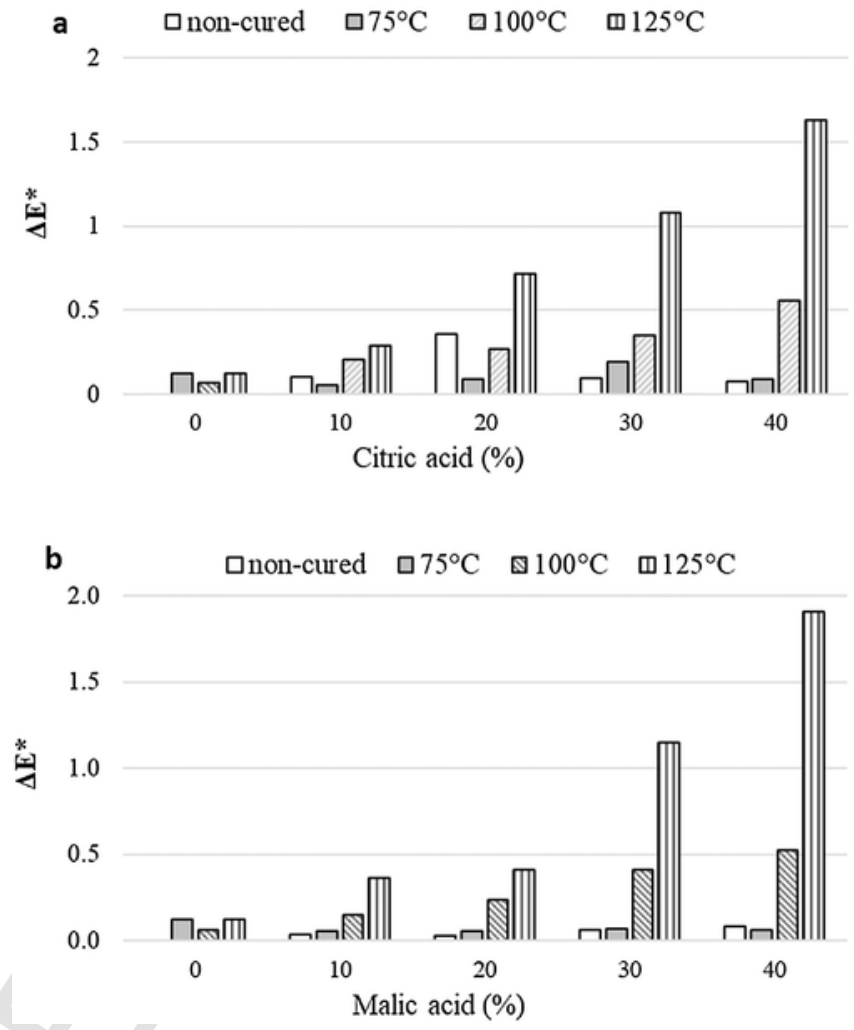

Fig. 5. Effect of citric (a) and malic (b) acid addition and heat curing on the overall color change $\left(\Delta \mathrm{E}^{*}\right)$ of $\mathrm{PVOH}$ film samples as compared with virgin films.

for citric acid-added samples. These values were not significantly different from those of the control films, moreover, no significant change in the transparency value was observed with increasing citric or malic acid addition. This suggests the food compatibility of the organic acids with the polymer matrix, which results in no appreciable light scattering, allowing the maintenance of high transparency of the film.

\section{Conclusion}

Citric and malic acid may exert multiple functions in PVOH films for food packaging use, such as plasticizers, esterifying and crosslinking agents and active compounds to be released on the food surface. Results highlight a significant effect of the organic acid $\times$ heat treatment interaction on the mechanical, physical and optical properties of PVOH films. In particular, this study points out that the use of citric and malic acid coupled with heat curing for the improvement of $\mathrm{PVOH}$ performances allowed to obtain active films with good tensile strength and extensibility, as the result of the plasticizer and crosslinker role in the polymer matrix: this represents an advantage compared to common plasticizers and crosslinkers, which improve one of these characteristics at the expense of the other. Moreover, the inclusion of organic acids into the PVOH matrix reduced hydrophilicity of $\mathrm{PVOH}$, especially when coupled with curing at high temperature, and neither the organic acid addition nor the thermal curing affected transparency, which is a valuable feature of $\mathrm{PVOH}$. Unlike a conventional crosslinking or plasticizer, whose incorporation and linkage to the film matrix should be maximized to minimize migration to the food, the incorporation of food-grade organic acids in active films implies a certain part to remain unreacted and available for diffusion from the film to the food. In this way, the active compound can exert its positive (i.e., antimicrobial) effect on the food surface throughout shelf life. The suitable combination of thermal curing and organic acid addition, thus, represents a promis- 
ing strategy for the improvement of $\mathrm{PVOH}$ properties and for tailoring the film physical and mechanical characteristics to the required levels.

\section{References}

Birck, C., Degoutin, S., Tabary, N., Miri, V., Bacquet, M., 2014. New crosslinked cast films based on poly (vinyl alcohol): Preparation and physico-chemical properties. eXPRESS Polymer Letters 8 (12), 941-952.

Chiellini, E., Corti, A., d'Antone, S., Solaro, R., 2003. Biodegradation of poly (vinyl alcohol) based materials. Progress in Polymer Science 28 (6), 963-1014.

Demerlis, C.C., Schoneker, D.R., 2003. Review of the oral toxicity of polyvinyl alcohol (PVA). Food and Chemical Toxicology 41, 319-326.

Gan, I., Chow, W.S., 2018. Antimicrobial poly(lactic acid)/cellulose bionanocomposite for food packaging application: A review. Food Packaging and Shelf Life 17, 150-161.

Gohil, J.M., Bhattacharya, A., Ray, P., 2006. Studies on the crosslinking of poly (vinyl alcohol). Journal of Polymer Research 13, 161-169.

Han, J.H., Floros, J., 1997. Casting antimicrobial packaging films and measuring their physical properties and antimicrobial activity. Journal of Plastic Film and Sheeting 13, 287-298.

Ingrao, C., Gigli, M., Siracusa, V., 2017. An attributional Life Cycle Assessment application experience to highlight environmental hotspots in the production of foamy polylactic acid trays for fresh-food packaging usage. Journal of Cleaner Production 150, 93-103.

Lim, M., Kwon, H., Kim, D., Seo, J., Han, H., Khan, S.B., 2015. Highly-enhanced water resistant and oxygen barrier properties of cross-linked poly(vinyl alcohol) hybrid films for packaging applications. Progress in Organic Coatings 85, 68-75.

Liu, J., Zheng, X.J., Tang, K.Y., 2013. Study on the gravimetric measurement of the swelling behaviours of polymer films. Reviews of Advanced Materials Science 33, 452-458.

Mohsin, M., Hossin, A., Haik, Y., 2011. Thermal and mechanical properties of poly(vinyl alcohol ) plasticized with glycerol. Journal of Applied Polymer Science 122 (5), 3102-3109.
Muppala, S.R., Kannat, S.R., Chawla, S.P., Sharma, A., 2014. Carboxymethyl cellulose-polyvinyl alcohol films with clove oil for active packaging of ground chicken meat. Food Packaging and Shelf Life 2, 51-58.

Musetti, A., Paderni, K., Fabbri, P., Pulvirenti, A., Al-moghazy, M., Fava, P., 2014. Poly(vinyl alcohol)-based film potentially suitable for antimicrobial packaging applications. Journal of Food Science 79 (4), E577-E582.

Park, J.S., Park, J.W., Ruckenstein, E., 2001. Thermal and dynamic mechanical analysis of PVA/MC blend hydrogels. Polymer 42 (9), 4271-4280.

Park, S.Y., Jun, S.T., Marsh, K.S., 2001. Physical properties of PVOH/chitosan-blended films cast from different solvents. Food Hydrocolloids 15 (4-6), 499-502.

Pawde, S.M., Deshmukh, K., 2008. Characterization of polyvinyl alcohol/gelatin blend hydrogel films for biomedical applications. Applied Polymer Science 109 (5), 3431-3437.

Quintero, S.M.M., Ponce, R.V.F., Cremona, M., Triques, A.L.C., Almeida, A.R., Braga, A.M.B., 2010. Swelling and morphological properties of poly (vinyl alcohol) (PVA) and poly (acrylic acid) (PAA) hydrogels in solution with high salt concentration. Polymer 51 (4), 953-958.

Shi, R., Bi, J., Zhang, Z., Zhu, A., Chen, D., Zhou, X., et al., 2008. The effect of citric acid on the structural properties and cytotoxicity of the polyvinyl alcohol / starch films when molding at high temperature. Carbohydrate Polymers 74, 763-770.

Vieira, M.G.A., Altenhofen da Silva, M., Oliveira dos Santos, L., Beppu, M.M., 2011. Natural-based plasticizers and biopolymer films: A review. European Polymer Journal 47 (3), 254-263. https://doi.org/10.1016/j.eurpolymj.2010.12.011.

Yoon, S.D, Chough, S.H., Park, H.R., 2007. Preparation of resistant starch/poly(vinyl alcohol) blend films with added plasticizer and crosslinking agents. Journal of Applied Polymer Science 106 (4), 2485-2493.

Yoon, S., 2014. Cross-linked potato starch-based blend films using ascorbic acid as a plasticizer. Journal of Agricultural and Food Chemistry 62, 1755-1764.

Zou, G.-X., Qu, J.-P., Zou, X.-L., 2007. Optimization of water absorption of starch/PVA composites. Polymers and Polymer Composites 28 (5), 674-679. 